\title{
Microwave Assisted Reduction of Chalcones: A Versatile Method
}

\author{
Wender A. Silva*, Lennine R. Melo and Júlia Galvez B. Pedreira.
}

Laboratório de Quimica Metodológica e Orgânica Sintética (LaQMOS), Instituto de Química, Universidade de Brasília, C.P. 4478 ,70910-970, Brasília, D.F., Brasil

*e-mailwender@unb.br

Keywords: Chalcones, Microwave Irradiations and Ammonium Formate

\section{INTRODUCTION}

Although there are several methods of $\alpha, \beta$ unsaturated systems reduction, ${ }^{1}$ but there are few effective methods for the reduction of chalcones to their respective saturated alcohols which opens possibilities for the development of new and attractive methods to obtain this type of system using microwaves irradiation ${ }^{2}$. The main goal of this work is to develop a new approach to racemic reduction of chalcones, with palladium assisted by microwave irradiation. The process use a cheap reducing agent, which decreased reaction times to minutes when compared to the conventional one. ${ }^{3}$ Chalcones were studied because they are important intermediates in the synthesis of potential immunosuppressive agents

\section{RESULTS AND DISCUSSION}

A sealed $10 \mathrm{~mL}$ glass tube containing the chalcone (1 $\mathrm{mmol}), \mathrm{Pd} / \mathrm{C} 10 \%(0,01 \mathrm{~mol})$ and the ammonium formate $(10 \mathrm{mmol})$ was introduced in the cavity of a microwave reactor (CEM Co., Discover) and irradiated for 1,5-3 min (60 W) under magnetic stirring. The temperature increased to until $55-60^{\circ} \mathrm{C}$. The reactions were monitored by TLC and after completion the glass tube was cooled and the

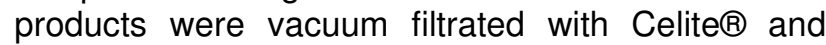
weighed for yield determination.

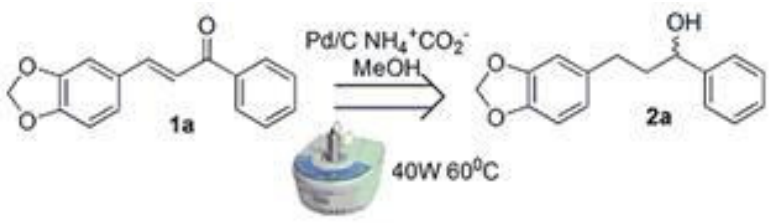

Scheme 1. Reduction of Chalcones

After determining optimal condition with $1 \mathrm{a}$, other chalcones were tested. The chosen chalcones had donor or withdrawing groups, present, in their aromatic rings, Figure 1, and the results are shown in Table 1. The products were obtained in excellent yields in extremely short time when compared with reduction under thermal conditions, about $4 \mathrm{~h}$.
Another important point about this method was that the reagents did not suffers degradation with heating.
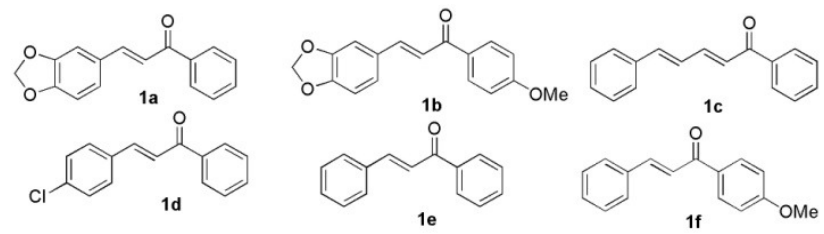

Figure 1. Chalcones used in this study.

Chalcones with heteroaromatic rings and other types of substituents will be used with the intention of evaluating e this new methodology.

Table 1. Results of the reductions studies.

\begin{tabular}{cccc}
\hline Entry & Chalcone & Time (min) & Yield (\%) \\
\hline 1 & 1a & 3,0 & Quantitative \\
2 & 1b & 1,5 & Quantitative \\
3 & 1c & 1,5 & Quantitative \\
4 & 1d & 3,0 & Quantitative \\
5 & 1e & 1,5 & Quantitative \\
6 & 1f & 1,5 & Quantitative \\
\hline
\end{tabular}

\section{CONCLUSION}

In conclusion, a mild and efficient MWA methodology employing $\mathrm{Pd} / \mathrm{C}$ and ammonium formate for the preparation of racemic alcohols from chalcones has been developed.

\section{ACKNOWLEDGEMENTS}

IQ-UnB, PIBIC-CNPq, FINEP-CT INFRA no 0970/01

\section{REFERENCES}

1 J.G. Handique, A. Purkayashtha, J.B. Baruah, J. Organomet. Chem., 2001, 620, 90.

2 Schmöger,C.; Stolle, A.; Bonratha, W.; Ondruschka,B.; Current Organic Chemistry, 2011, 15, 151.

3 Andrade, C. K. Z.; Silva, W. A.; Lett. Org. Chem. 2005

$14^{\text {th }}$ Brazilian Meeting on Organic Synthesis $-14^{\text {th }}$ BMOS - September 01-05, 2011-Brasilia, Brazil 